\title{
Influence of Martensite Volume Fraction on Ductile to Brittle Transition of Triple Phase Ferrite-Perlite-Martensite Steels Joined by GMAW and Electrical Arc Welding
}

\author{
M. EKICI ${ }^{a}$ AND U. OZSARAC ${ }^{b}$ \\ ${ }^{a}$ Yalova University, Vocational School of Yalova, Yalova, Turkey \\ ${ }^{b}$ Sakarya University, Faculty of Technology, Department of Metallurgical and Materials Engineering \\ Esentepe Campus, Sakarya, Turkey
}

\begin{abstract}
In this study, the effect of martensite volume fraction on ductile to brittle transition of microalloyed steel joined by welding was investigated. Triple phase steel contains ferrite, perlite and martensite phases and was joined by two types of welding method as gas metal arc welding and the electric arc welding. Presence of three phases in adjacent to each other was confirmed by metallographic analysis and scanning electron microscopy studies. All welded samples were exposed to Charpy impact test at the temperature range of $-30{ }^{\circ} \mathrm{C}$ to $30^{\circ} \mathrm{C}$ in order to measure the fracture energies of samples having different amount of martensite volume fractions. The fracture surface micrographs of Charpy specimens, examined by scanning electron microscopy and optical microscopy, confirmed the reduction in ductility of ferrite-perlite-martensite steels with increasing martensite volume fraction.
\end{abstract}

DOI: $10.12693 /$ APhysPolA.125.529

PACS: 81.20.Vj, 81.70.Bt, 81.05.-t, 81.05.Bx

\section{Introduction}

In view of their capacity to develop high strength following limited alloying and ease of processing, medium carbon microalloyed steels are very cost-effective compared with quenched and tempered steels for the production of automotive components. To be able to substitute quenched and tempered steels, medium carbon microalloyed steels must be processed to similar strength levels and acceptable toughness [1]. To increase toughness, the carbon level of the medium carbon microalloyed steels is reduced and the decrease in strength due to a reduction in the carbon level is compensated by the addition of $\mathrm{Mn}$ and Si. A further increase in strength is achieved by the precipitation strengthening through microalloying with vanadium [2].

Recently, a two-step cooling and annealing treatment was developed to produce multiphase (ferrite-bainitemartensite) microstructures that displayed tensile properties similar to those of quenched and tempered steels. It was reported that a decrease in the final formation temperature led to a finer grain size (beneficial for toughness) and also promoted the formation of ferrite $[2,3]$.

The room temperature cyclic stress-strain and low cycle fatigue behaviour of this material having multiphase (ferrite-bainite-martensite) microstructure was established and compared with that of the ferrite-pearlite and the tempered martensite microstructures. Despite the observed cyclic strain softening, the ferrite-bainitemartensite microstructure was cyclically stronger than the tempered martensite and the ferrite-perlite microstructures. When plotted against the total strain amplitude $\left(\Delta \varepsilon_{\mathrm{t}} / 2\right)$, the low cycle fatigue lives were rather similar for all the three microstructures [4]. In present study, micro-alloyed steels were tried to join by two different welding methods namely gas metal arc welding (GMAW) and the electric arc welding by using different filler materials, and the fracture energy properties of butt welded specimens were measured by destructive tests.

\section{Experimental studies}

Triple phase ferrite-perlite-martensite steel was selected as base metal at the beginning of this study, because triple phase ferrite-perlite-martensite steels have good welding ability and are commonly used in industry. Two types of welding methods were applied in order to compare the efficiencies of welding operations. The chemical composition of base metal triple phase ferriteperlite-martensite steels and all filler materials used in experiments were given in Table I. Two types of welding methods welding parameters were given in Table II.

TABLE I

The chemical compositions of base metal and filler materials used in experiments (wt\%).

\begin{tabular}{c|c|c|c|c|c|c|c}
\hline \hline Materials & $\mathrm{C}$ & $\mathrm{Si}$ & $\mathrm{Mn}$ & $\mathrm{Mo}$ & $\mathrm{Ni}$ & $\mathrm{Cu}$ & $\mathrm{V}$ \\
\hline base metal & 0.322 & 0.212 & 1.386 & 0.043 & 0.094 & 0.124 & 0.123 \\
ER 100 SG & 0.08 & 0.44 & 1.70 & 0.30 & 1.35 & 0.25 & 0.08 \\
Fox Ev 85 & 0.05 & 0.40 & 1.50 & 0.50 & 2.00 & - & -
\end{tabular}

\section{Results and discussion}

GMAW and electric arc welding were applied to triple phase ferrite-perlite-martensite steels and butt welded specimens were exposed to Charpy impact test at the 
TABLE II

GMAW and electrical arc welding parameters.

\begin{tabular}{c|c|c}
\hline \hline $\begin{array}{c}\text { Welding } \\
\text { parameters }\end{array}$ & $\begin{array}{c}\text { Gas metal } \\
\text { arc welding }\end{array}$ & $\begin{array}{c}\text { Electrical } \\
\text { arc welding }\end{array}$ \\
\hline $\begin{array}{c}\text { shielding gas } \\
\text { welding wire }\end{array}$ & $15 \mathrm{CO}_{2}+85 \mathrm{Ar}$ & - \\
and electrodes & ER $100 \mathrm{SG}$ & Fox Ev 85 \\
wire diameter & $1.2 \mathrm{~mm}$ & $3.25 \mathrm{~mm}$ \\
arc current [A] & 150 & 150 \\
arc voltage [V] & 22 & 22
\end{tabular}

temperature range of $-30{ }^{\circ} \mathrm{C}$ to $30^{\circ} \mathrm{C}$ in order to measure the fracture energies of samples having different amount of martensite volume fractions. The obtained results were shown in Fig. 1. GMAW values are higher than that of arc welding ones. GMAW group specimens have the highest fracture energies values, but of course these values are also lower than that of base metal's which was not exposed to welding.

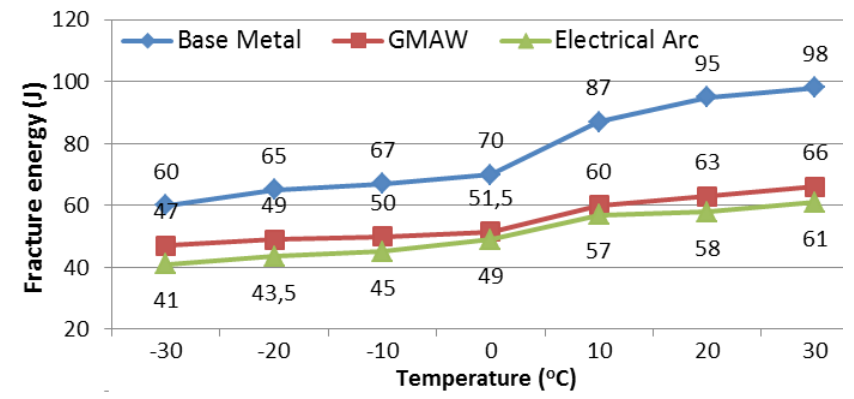

Fig. 1. Charpy impact test results of all specimens.

The hardness (HRC) values of butt welded specimens were measured from nine different points. The mean values of two measurements in all group specimens were shown in Fig. 2. The highest hardness values were gained in electric arc welded specimens and hardness values of base metal group specimens have the lowest values. The hardness increases from base metal to heat affected zone (HAZ) and reaches the maximum values in weld zone. This tendency was seen in all specimens.
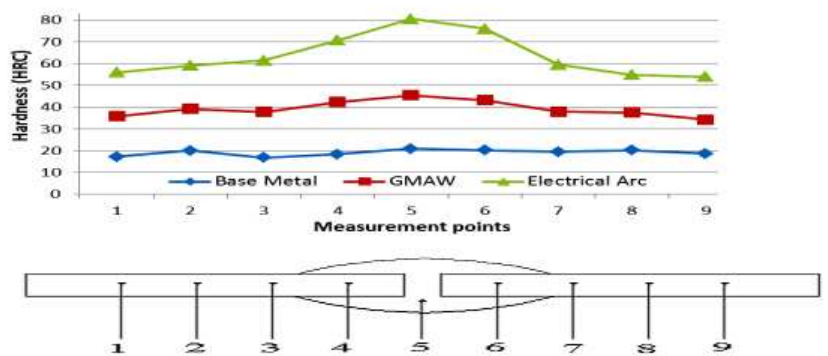

Fig. 2. Hardness measurement points and values.

Martensite volume fraction and microstructures of all specimens detected with optical microscope are given in Fig. 3 and Fig. 4, respectively.

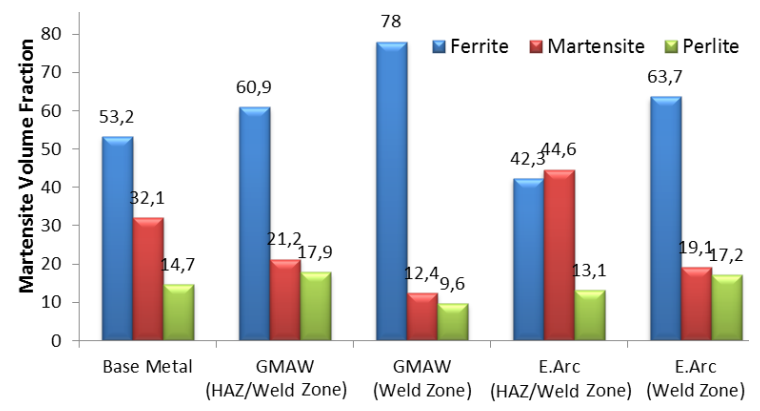

Fig. 3. Martensite volume fraction results of all specimens.

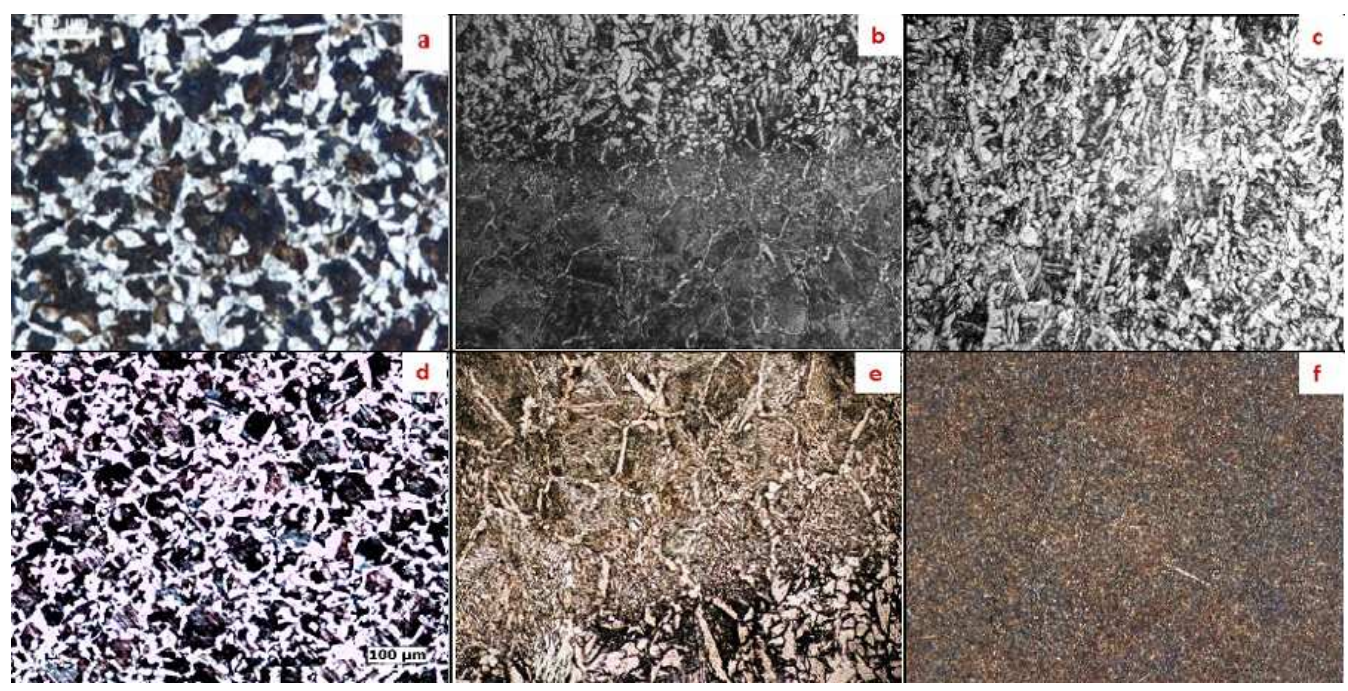

Fig. 4. Microstructures of (a) base metal, (b) HAZ/weld zone GMAW, (c) weld zone in GMAW, (d) base metal, (e) base metal/HAZ interface in electric arc welded specimens, (f) weld zone in electric arc welded specimens. 


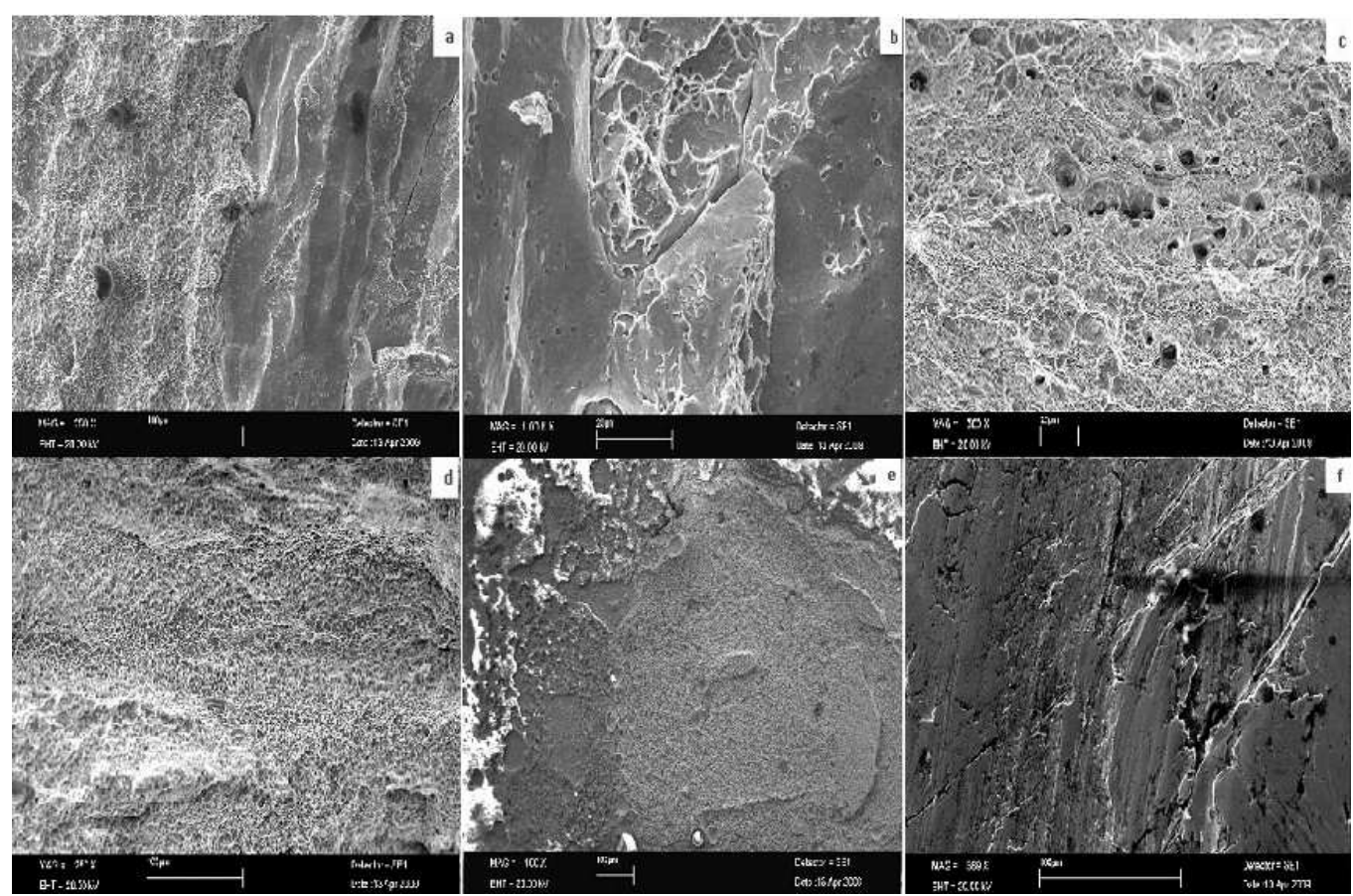

Fig. 5. SEM micrograph of $(a, b, c)$ fracture surface of electric arc welded samples joined by Fox Ev 85 electrode, $(d, e, f)$ fracture surface of GMAW samples joined by ER 100 SG welding wire.

Worn surfaces of the welded and weldless plates and fracture surface of notch impact test samples have been investigated by means of scanning electron microscope (SEM). The SEM micrographs of fracture surfaces of fillet welded samples after Charpy impact test were given in Fig. 5, and from brittle to ductile fracture manner have been observed with increasing test temperature from $0^{\circ} \mathrm{C}$ to $30{ }^{\circ} \mathrm{C}$.

\section{Conclusion}

It was concluded from this study that GMAW gas composition with $15 \% \mathrm{CO}_{2}+85 \%$ Ar by means of ER 100 SG filler wire must be selected in order to obtain the fracture energy and optimum hardness and ductility values in joining of micro-alloyed steels. In general, it can be said that the fracture energies for each sample by looking at the work areas are generally between $0{ }^{\circ} \mathrm{C}$ to $+30^{\circ} \mathrm{C}$ to determine. Electric arc welding method should not be preferred, because welding faults like gas hole and slag formation can occur as seen in SEM photos and lower strength values were obtained.

\section{References}

[1] D.K. Matlock, G. Krauss, J.G. Speer, J. Mater. Process. Technol. 117, 324 (2001).

[2] I. Gonzalez-Baquet, R. Kaspar, J. Richter, Steel Res. 68, 61 (1997).

[3] I. Gonzalez-Baquet, R. Kaspar, J. Richter, G. Nussbaum, A. Koethe, Mater. Sci. Forum 284-286, 411 (1998).

[4] S. Sankaran, V.S. Sarma, K.A. Padmanabhan, Mater. Sci. Eng. A 345, 328 (2003). 